\title{
Trace elemental analysis of mitral valves by EDXRF
}

\author{
A. Ates ${ }^{\mathrm{a}, *}$, O. Simsek ${ }^{\mathrm{b}}$, B. Ertugral ${ }^{\mathrm{c}}$ and M. Ertugrul ${ }^{\mathrm{d}}$ \\ ${ }^{a}$ Department of Cardiovascular Surgery, Faculty of Medicine, Atatürk University, Ezurum, Turkey \\ ${ }^{\mathrm{b}}$ Department of Physics, Faculty of Education, Atatürk University, Ezurum, Turkey \\ ${ }^{\mathrm{c}}$ Department of Physics, Faculty of Art and Sciences, Karadeniz, Technical University, Trabzon, Turkey \\ ${ }^{\mathrm{d}}$ Department of Electrical and Electronic, Faculty of Engineering, Atatürk University, Ezurum, Turkey
}

\begin{abstract}
The elemental analysis of mitral valves from 12 patients with rheumatic mitral valve disease was performed using radioisotope excited energy dispersive X-ray fluorescence (EDXRF) technique. An annular $50 \mathrm{mCi}{ }^{55} \mathrm{Fe}$ radioactive source was used for excitation of characteristic K X-rays of the trace elements in the samples. A high resolution $\mathrm{Si}(\mathrm{Li})$ detector, which has a $160 \mathrm{eV}$ full width at half maximum for $5.9 \mathrm{keV}$ photons, was used for intensity measurements. Concentrations of the elements $\mathrm{P}, \mathrm{S}, \mathrm{K}$ and $\mathrm{Cl}$ in the mitral valve samples were determined by using standard addition method. Deficiencies or excesses of these trace elements cause the valves to run irregularly. Abnormal value of these elements may also result in rheumatic valve disease. Keywords: Qualitative and quantitative analysis, mitral valve, energy dispersive X-ray fluorescence (EDXRF)
\end{abstract}

\section{Introduction}

Energy dispersive X-ray fluorescence (EDXRF) technique has become a powerful technique for nondestructive multi-element analysis of materials. EDXRF has in recent years increasingly been applied to the analysis of vegetables, aerosols, waters, sediments, soils, solid waste, medical and other environmental samples. EDXRF can be applied to any kind of sample, liquid, solid, thick, intermediate or thin with, in many cases, sufficient sensitivity for many trace elements. The EDXRF was used for the determination of trace elements of different samples such as some lichens, tobaccos, coles, sea sediments, red mud, medicinal plants, blood, ash of power plants, etc. [1-12].

A major goal for research in biomedical sciences over the last few decades has been to determine the concentrations of various elements in human tissues. In recent years, large increase in research work related to bio-medical field such as blood, human head hair, kidney stones, human teeth and bones have made it desirable to improve the application of EDXRF analysis [13]. EDXRF technique combined with simple procedures of sample preparation such as drying of a few droplets of liquid on filter paper allow measurement of calcium, potassium, chlorine, sulfur and phosphorus in blood serum and in cellular fluids. Ashes of tissue, serum and bones may be analyzed for heavy elements such as iron, zinc, copper and strontium. EDXRF technique further allows to detect electrophoretically separated protein fractions of the serum and to detect pathologic changes.

\footnotetext{
${ }^{*}$ Corresponding author: A. Ates, Department of Cardiovascular Surgery, Faculty of Medicine, Atatürk University, 25240 Ezurum, Turkey. Fax: +90 442 2360955; E-mail: aates@ atauni.edu.tr.
} 
Trace elements are essential to humans. Both deficiencies and excesses of the concentrations of these trace elements may result in a number of disorders in the human body. On the other hand, the toxic elements are known to be very harmful even at extremely low concentrations. For this reason, elemental analysis is highly important as a research and diagnostic tool in medicine. Much research has been carried out to elucidate the effects of the accumulation of certain elements by some organs, which results in diseases and disorders in these organs $[14,15]$. Besides, a variety of bio-medical samples have been analyzed by various authors in recent years, Al-Kofahi and Hallak [16] analysed kidney stones by PIXE and RBS techniques. Carvalho et al. [17] analyzed human teeth and bones from the chalcolithic period by X-ray spectrometry. Carvalho and Marques [18] reported quantitative analysis of healthy liver, brain and kidney tissues and the corresponding tissues from subjects suffering from liver cirrhosis.

The human heart consists of four chambers; two upper chambers (the atria) and two lower chambers (the ventricles) that are responsible for pumping blood. The heart valves are like one-way doors, which open and close with each beat of the heart, controlling the blood flow from one chamber to the next. Each of these valves is made up of a few thin folds of tissue. When functioning correctly, they keep blood from flowing backward into a chamber when closed.

In the etiology of cardiac valve disease, different factors have role such as conjunctional reasons, infection, rheumatic fever, trauma and degeneration. While the most frequent reason which is related to the length of human life in developed countries is degenerative, valve disease gets more importance. Recently, although rheumatic valve disease has remarkably decreased in our country, it is still an important health problem of common people.

Rheumatic valve disease has the most frequent influence on mitral valve. Only mitral valve is affected in $50-60 \%$ by rheumatic fever cases. $20 \%$ aorta valve is affected along with mitral valve. Only aorta valve is affected in $10 \%$. Tricuspid valve ecliptic has not usually been insulated, but it happens with aorta valve ecliptic and it is determined in $10 \%$ of all cases.

Valve coarseness due to rheumatic fever attack or attacks, retractions, calcification, commissural cordal stickiness constitute acute valve ecliptic. This pathological process is concluded by narrowness, and inadequacy on the valve or in general both of them are together $[19,20]$. While $25 \%$ of rheumatic mitral valve disease is from pure mitral narrowness, $40 \%$ of it has been together with mitral inadequacy and narrowness. $2 / 3$ of the patients are women.

Mitral valves contain some trace elements such as P, S, K and Cl. Both deficiencies and excesses of the concentrations of these trace elements cause the valves to run irregularly and may result in rheumatic valve disease. In the present paper, we have obtained the elemental composition of mitral valves collected from 12 patients with rheumatic mitral valve disease by using EDXRF. We have determined concentrations of the elements $\mathrm{P}, \mathrm{S}, \mathrm{Cl}, \mathrm{K}$ and $\mathrm{Ca}$ in the mitral valve samples.

\section{Experimental procedure}

\subsection{Method}

The standard addition method was used to obtain the elemental concentrations. The method involves the addition of known quantities of the analyte to the specimen. If analyte is present at low levels and no suitable standards are available, standard addition may prove to be an alternative, especially if the analyst is interested in only one analyte element. The principle is the following: adding a known amount 
of analyte $i\left(\Delta W_{i}\right)$ to the unknown sample gives an increased intensity $I_{i}+\Delta I_{i}$. Assuming a linear calibration, the following equations apply:

$$
I_{i}=M_{i} W_{i}
$$

for the original samples and

$$
I_{i}+\Delta I_{i}=M_{i}\left(W_{i}+\Delta W_{i}\right)
$$

for the sample with the addition. Thus, the method assumes that linear calibration is adequate throughout the range of addition because it assumes that an increase in the concentration of analyte by amount $\Delta W_{i}$ will increase the intensity by $M_{i} \Delta W_{i}$. These equations can be solved for the weight fraction of element $i$ $\left(W_{i}\right)$. To check the linearity of the calibration, the process can be repeated by adding different amounts of the analyte to sample and plotting the intensity measured versus the concentrations added. The intercept of the line on the concentration axis equals $W_{i}$. The intensities used for calibration must be corrected for background and line overlap.

\subsection{Sample preparation}

The Mitral valve samples were collected from 12 patients with rheumatic mitral valve disease whose heart valves were replaced with artificial heart valves in open-heart surgeries carried out in the Ataturk University Research Hospital. Each sample was dried using ovens and then powdered using a Spex mill. Finally, it was mixed according to spectroscopic methods. This process was carried out for all the 12 samples under investigation. To provide particle size homogeneity, samples were sieved using a 400 mesh sieve. Twenty milligrams of this powder was spread homogeneously on a mylar film stretched across a fibre frame.

\subsection{Excitation and spectral analysis}

The geometry and the shielding arrangement of the experimental setup employed in the present study are as shown in Fig. 1. The spectra were recorded by the $\mathrm{Si}(\mathrm{Li})$ detector coupled to a multi-channel analyzer through a spectroscopic amplifier. The energy resolution of the detector system was $160 \mathrm{eV}$ FWHM for the $\mathrm{MnK}_{\alpha}$ line at $5.96 \mathrm{keV}$.

To obtain the standard addition curve used for evaluation of concentration of each element in mitral valve samples, a series of individual standards have been added. To this aim, spectroscopically pure powders of $\mathrm{P}, \mathrm{S}, \mathrm{K}$ and $\mathrm{Cl}$ have been used for addition. Photons of $5.96 \mathrm{keV}$ energy from Fe-55 annular source were used for excitation of the samples. The spectra were accumulated over 10,000 s in order to obtain sufficient statistical accuracy. In order to minimize the absorption effect, the $\mathrm{EK}_{\alpha} / \mathrm{MnK}_{\alpha}(\mathrm{E}=\mathrm{S}$, $\mathrm{P}, \mathrm{Cl}, \mathrm{K}$ ) intensity ratio was used instead of $\mathrm{EK}_{\alpha}$ intensity obtained from ${ }^{55} \mathrm{Fe}$. A representative example of a spectrum for mitral valve samples is shown in Fig. 2.

\section{Results and discussion}

Anomalies in concentrations of the trace elements in mitral valves play an important role in the rheumatic mitral valve diseases. However, the reason of anomalies in concentrations of the trace elements in the mitral valves is not known. It is uncertain that this is a result of this disease or one of 


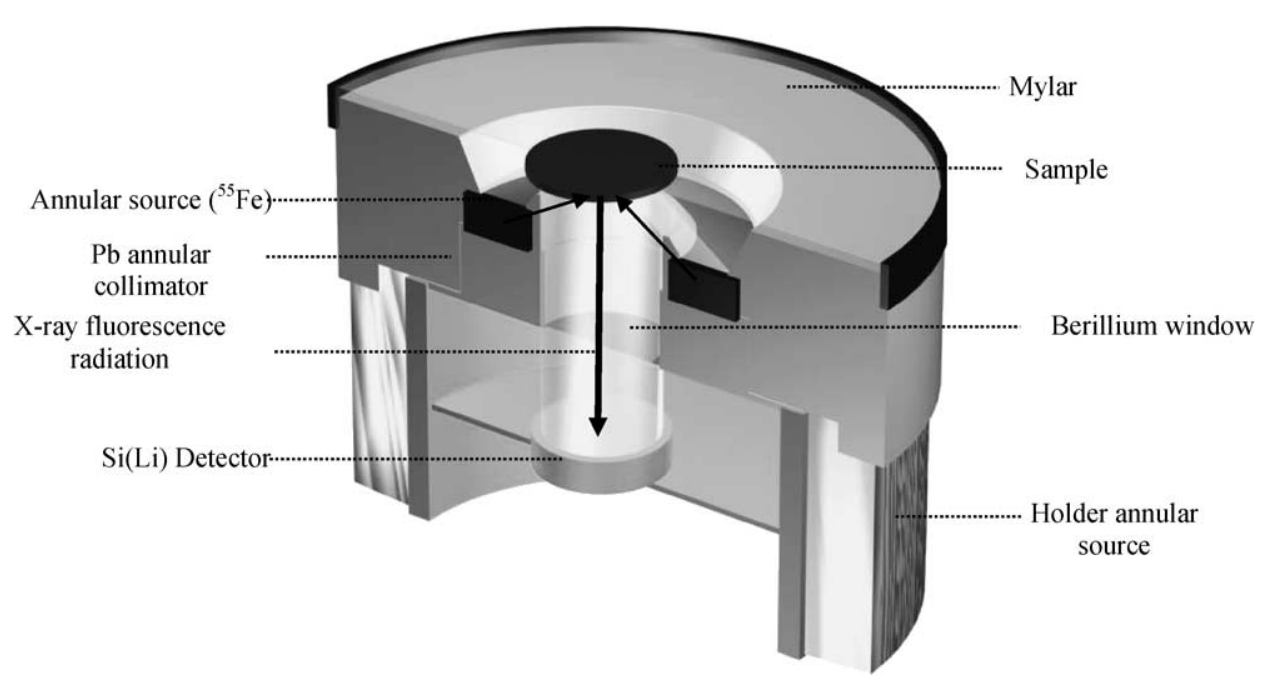

Fig. 1. The experimental setup.

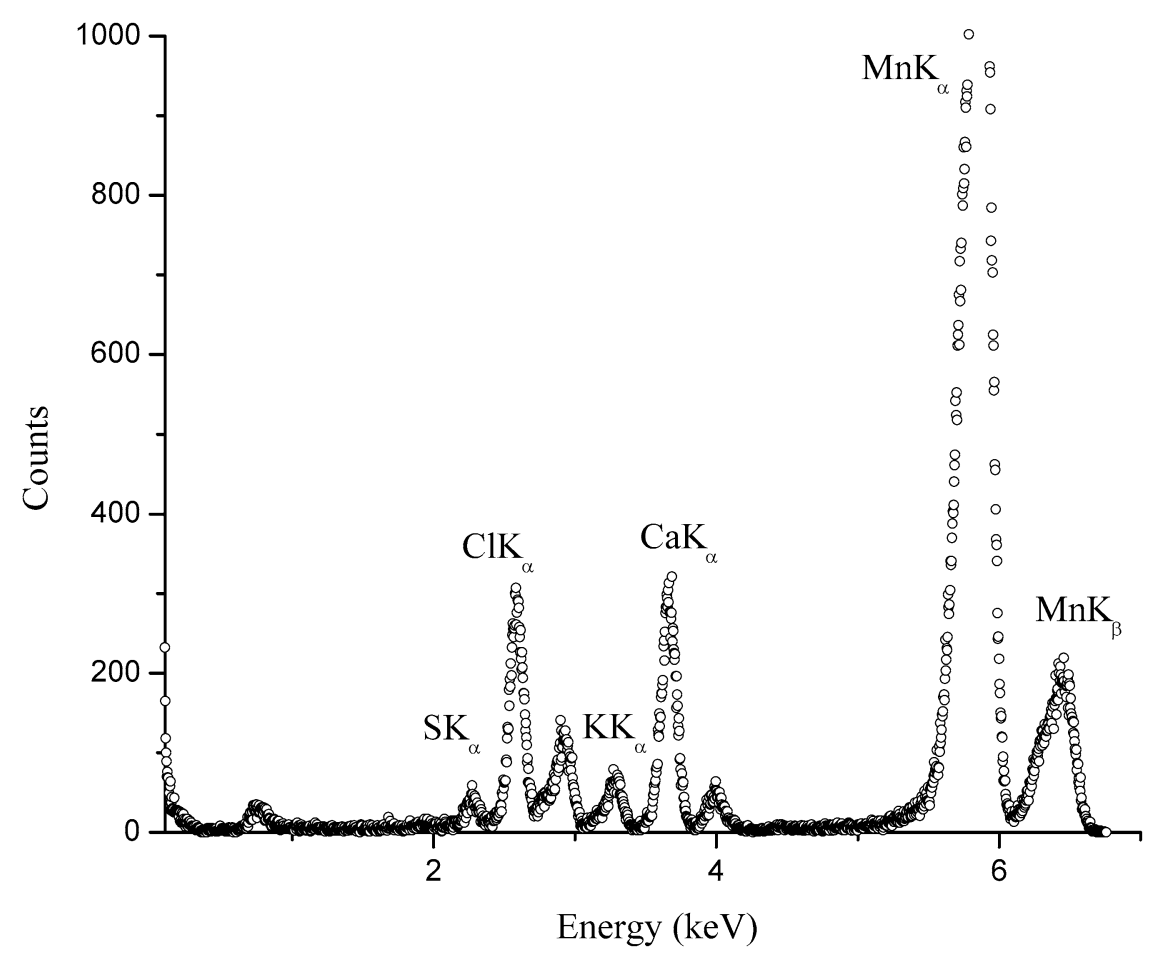

Fig. 2. A typical spectrum for mitral valve samples excited by ${ }^{55} \mathrm{Fe}$ radioactive source.

the reasons of the disease [21]. However, in their study, Durak et al. [22,23] reported that anomalies in concentrations of the trace elements in mitral valves may be a result of the disease.

The concentrations of the trace elements in mitral valve samples from 12 patients with rheumatic mitral valve diseases are presented in Table 1. From the Table 1, it can be seen that concentration ranges of this elements in the samples are very large. 
Table 1

Elemental concentrations in mitral valve samples

\begin{tabular}{lcccc}
\hline Samples & \multicolumn{4}{c}{ Elemental concentrations (\%) } \\
\cline { 2 - 5 } & $\mathrm{P}$ & $\mathrm{S}$ & $\mathrm{K}$ & $\mathrm{Cl}$ \\
\hline 1 & - & 1.34 & 0.31 & 3.36 \\
2 & - & 0.90 & 1.41 & 1.07 \\
3 & 3.46 & 0.61 & 0.15 & 2.79 \\
4 & 26.56 & 0.51 & - & 2.21 \\
5 & 23.88 & 1.02 & 0.15 & 1.49 \\
6 & 1.06 & 0.94 & 0.29 & 2.54 \\
7 & - & 0.49 & - & 2.77 \\
8 & - & 1.05 & 0.26 & 3.60 \\
9 & 0.46 & 1.24 & 0.28 & 2.85 \\
10 & - & 1.32 & 0.09 & 1.86 \\
11 & - & 0.93 & 0.23 & 4.31 \\
12 & 0.44 & 0.78 & 0.20 & - \\
\hline
\end{tabular}

In elemental analysis using X-ray fluorescence technique, matrix effects are known to distort the linearity of "photo peak area versus concentration" graphs for analyses. To minimize or to eliminate matrix effects we proceeded as follows:

(i) The $\mathrm{K}_{\alpha}$ net peak areas for $\mathrm{Cl}$ obtained from sample spectra were normalized by dividing them by $\mathrm{MnK}_{\alpha}$ peak areas.

(ii) To obtain an ideal grain size for the samples the ground material was sieved using a 400-mesh sieve.

In our measurements maximum relative errors due to the counting system were of the order $0.5-5 \%$. Errors originating from sample weighing, source intensity and system and system geometry were about $4 \%$. The combined relative error in our results was accordingly of the order of 5-7\%.

\section{Acknowledgements}

This work was done in Karadeniz Technical University, Physics Department, EDXRF Lab.

\section{References}

[1] E.I. Obiajunwa, A.C. Adebajo and O.R. Omobuwajo, Essential and trace element contents of some Nigerian medicinal plants, J. Radioanal. Nucl. Chem. 252 (2002), 473-476.

[2] A. Aslan, G. Budak, E. Tıraşoglu, A. Karabulut, Y. Karagoz, G. Apaydın, B. Ertugral and U. Çevik, Analysis of elements in some lichens by radioisotope X-ray fluorescence spectrometry, Fres. Environ. Bull. 13 (2004), 740-747.

[3] U. Cevik, E. Ergen, G. Budak, A. Karabulut, E. Tirasoglu, G. Apaydin and A.I. Kopya, Elemental analysis of Akcaabat tobacco and its ash by EDXRF spectrometry, JQSRT 78 (2003), 409-415.

[4] E. Tirasoglu, U. Cevik, B. Ertugral, G. Apaydın, H. Baltas and M. Ertugrul, Determination of trace elements in cole (Brassica oleraceae var. acephale) at Trabzon region in Turkey, J. Quan. Spectrosc. Radiat. Transfer 94 (2005), 181-187.

[5] M. Kobya, M. Ertugrul, O. Dogan and O. Simsek, Analysis of titanium and zirconium in red mud with energy dispersive X-ray spectrometry, Instrum. Sci. Technol. 24 (1996), 277-282.

[6] U. Cevik, A.I. Kopya, H. Karal and Y. Sahin, Quantitative analysis of sea-bed sediments from Eastern Black Sea by EDXRF spectrometry, J. Radioanal. Nucl. Chem. Lett. 201 (1995), 241-249. 
[7] A. Bumbalova, E. Havranek, M. Harangozo, E. Riecanska and E. Dejmkova, Multielement XRF-analysis of blood from patients with dilated cardiomyopathy, J. Radional. Nucl. Chem. Lett. 153 (1991), 257-265.

[8] O. Dogan, O. Simsek, Y. Nuhoglu, M. Kopya and M. Ertugrul, X-ray fluorescence spectrometry analysis of trace elements in fly ash samples of Kemerkoy thermal power plants, J. Trace Microprobe Tech. 19 (2001), 289-295.

[9] O. Dogan, O. Simsek, M. Ertugrul and M. Kopya, X-ray fluorescence spectrometry analysis of trace elements in fly ash samples of Yeniköy thermal power plants, Instrum. Sci. Technol. 29 (2001), 433-439.

[10] W.M. Kwiatek, B. Kubica, C. Paluszkiewicz and M. Galka, Trace elements analysis by means of synchroton radiation, XRF, and PIXE: Selection of sample preparation produce, J. Alloys Compd. 328 (2001), 283-288.

[11] Z.L.L. Yeung, R.C.W. Kwok and K.N. Yu, Determination of multi-element profiles of street dust using energy dispersive X-ray fluorescence (EDXRF), Appl. Radiat. Isot. 58 (2003), 339-346.

[12] N. Ekinci, G. Budak and A. Karabulut, Energy dispersive X-ray fluorescence spectrometry in the detection of İkizdere ore concentrates, JQSRT 75 (2002), 351-356.

[13] Sz. Törük, P. Van Dyck and V. Griken, Heterogenity effects in direct X-ray fluorescence analysis of hair, X-Ray Spectrom. 13 (1984), 27-32.

[14] E. Johansson, U. Lindh, H. Johansson and C. Sundstrom, Micro-PIXE analysis of macro- and trace elements in blood cells and tumors of patients with breast cancer, Nucl. Instrum. Methods B 22 (1987), 179-183.

[15] M. Uda, K. Meada, Y. Sasa, H. Kusuyama and Y. Yokode, An attempt to diagnose cancer by PIXE, Nucl. Instrum. Methods B 22 (1987), 84-187.

[16] M.M. Al-Kofahi and A.B. Hallak, Analysis of kidney stones by PIXE and RBS techniques, X-Ray Spectrom. 25 (1996), 225-228.

[17] M.L. Carvalho, C. Casaca, T. Pinheiro, J.P. Marques, P. Chevallier and A.S. Cunha, Analysis of human teeth and bones from the chalcolithic period by X-ray spectrometry, Nucl. Instrum. Methods 168 (2000), 559-565.

[18] M.L. Carvalho and A.F. Marques, X-ray fluorescence spectrometry: applications in trace elements studies in human tissues from patients with cirrhosis, X-Ray Spectrom. 30 (2001), 397-402.

[19] E. Braunwalde, Valvular hearth disease, in: Heath Disease a Textbook of Cardiovascular Medicine, 5th edn, E. Braunwald, ed., W.B. Saunders, Philadelphia, 1997, pp. 1007-1029.

[20] O.A. Smiseth, R. Bjorherheim and S. Nitler-Hauge, Noninvasive assessment of valvular function, in: M.H. Crawford and J.P. DiMarco, eds, Mosby, London, 2001, pp. 6(1,1)-6(1,5).

[21] S. Tohno, Y. Moriwake, Y. Tohno, T. Minami, F. Nishiwaki, M. Utsumi and M. Yamada, Age-related changes of element contents in human mitral and tricuspid valves, Biol. Trace Elem. Res. 70 (1999), 137-147.

[22] I. Durak, A. Sahin, Z. Yurtarslani and A. Sonel, Analysis of calcium, zinc, magnesium, iron and copper content in myocardium and stenosis mitral valves, Am. J. Cardiol. 64 (1989), 1392-1394.

[23] I. Durak, O. Akyol, M.U. Es, O. Canbolat and M. Akpoyraz, Element structure in stenosis mitral valves, Am. J. Cardiol. 71 (1993), 355-359. 


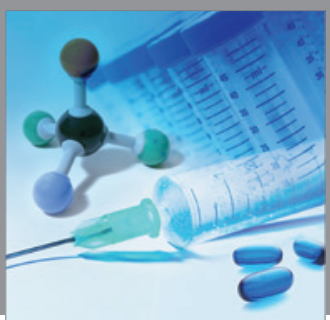

International Journal of

Medicinal Chemistry

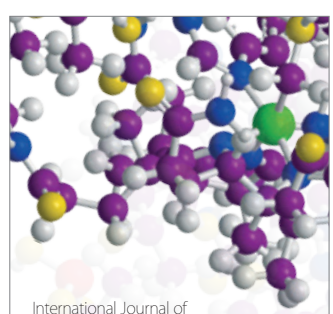

Carbohydrate Chemistry

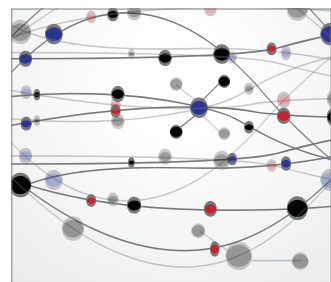

The Scientific World Journal
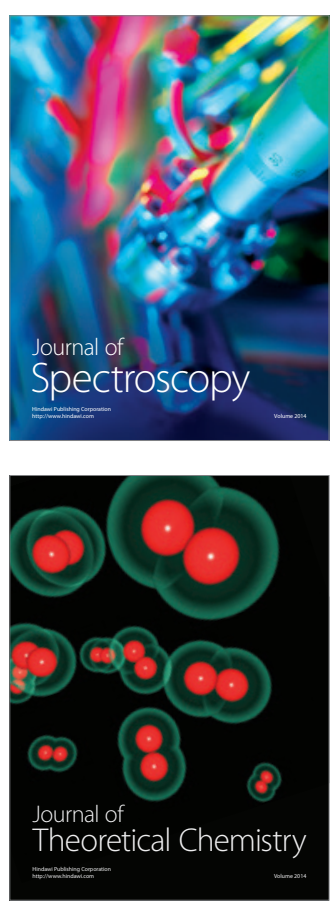
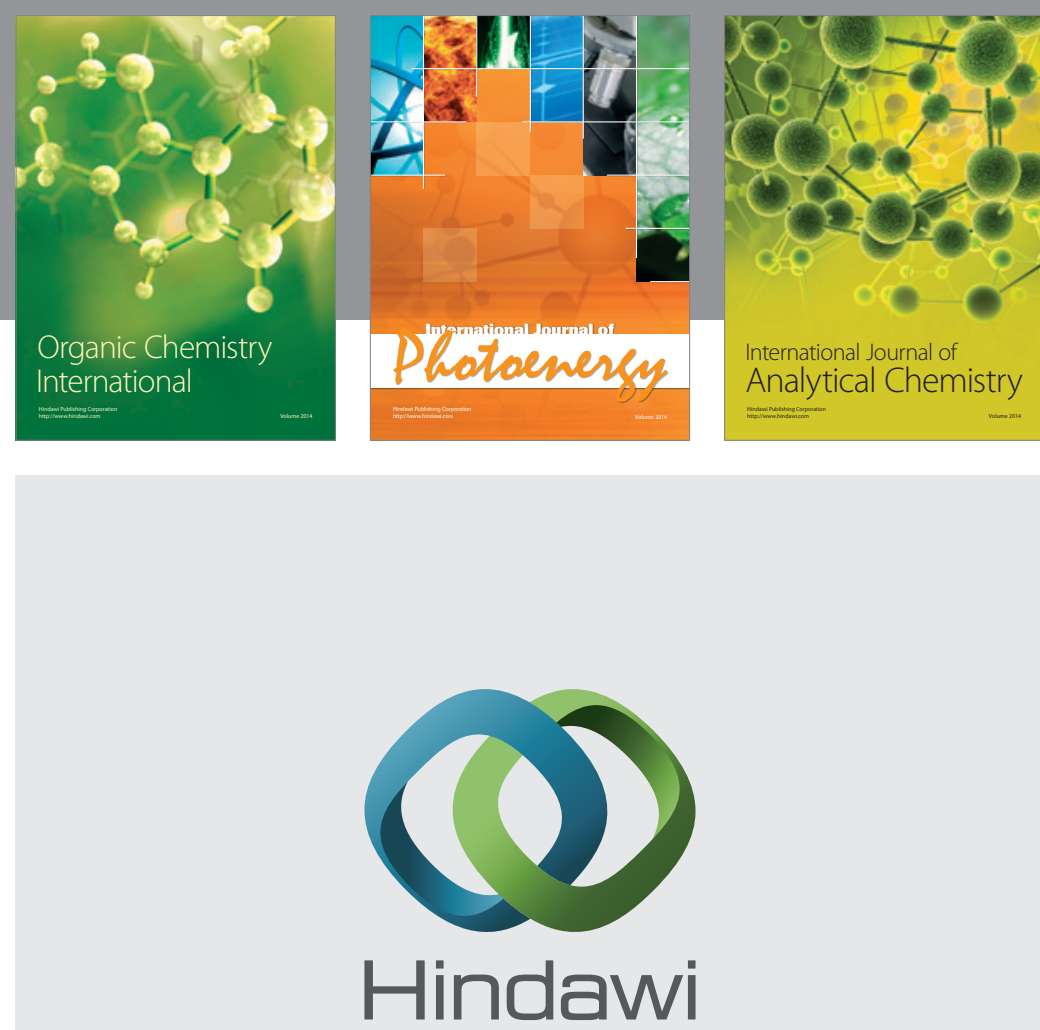

Submit your manuscripts at

http://www.hindawi.com
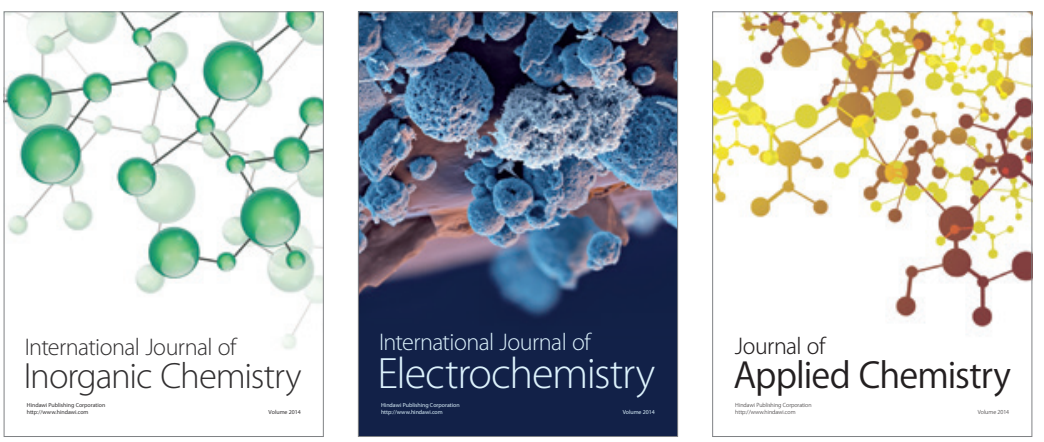

Journal of

Applied Chemistry
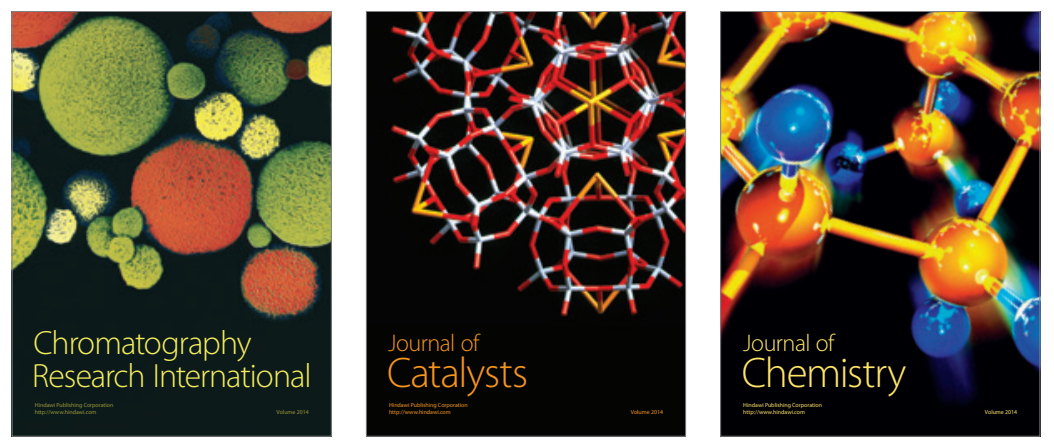
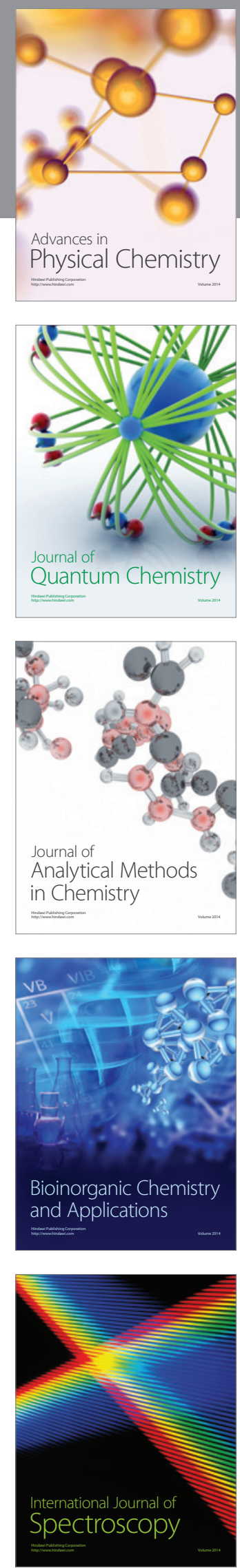